\title{
Densitometric patterns of spinal cord injury associated bone loss
}

\author{
SM Szollar ${ }^{2}$, EME Martin ${ }^{1}$, JG Parthemore ${ }^{1}$, DJ Sartoris ${ }^{3}$ and LJ Deftos ${ }^{1}$ \\ Department of Medicine, ${ }^{1}$ Department of Orthopedic Rehabilitation; ${ }^{2}$ Spinal Injury Unit, ${ }^{3}$ Department of Radiology, \\ University of California San Diego and the San Diego Veterans Affairs Medical Center, La Jolla, Ca 92161, USA
}

\begin{abstract}
The purpose of the study was to use dual energy X-ray absorptiometry to measure bone mineral density (BMD) in the lumbar spine, the femoral neck, Ward's triangle, and the greater trochanter in 204 men (69 able-bodies controls and 135 spinal cord injured patients) stratified according to age $(20-39,40-59$, and $60+$ years old $)$ in order to determine whether changes in BMD were age related, and to determine when these changes began to appear. The BMDs of the lumbar spine of both the 40-59 year old and the $60+$ year old patients were significantly higher $(P \leqslant 0.012)$ than the $40-59$ year old and $60+$ year old controls, respectively. The femoral region BMDs of the $20-39$ year old and the $40-59$ year old patients were all significantly lower $(P \leqslant 0.027)$ than the $20-39$ year old and $40-59$ year old controls, respectively. When patients were grouped according to the time since their injury $(0-1,1-5$, $6-9,10-19,20-29,30-39,40-49$, and 50-59 years post injury) within the various age categories different results were obtained. In all the age categories, BMD loss occurred starting one year after spinal cord injury in the hip region. This bone loss took place gradually, reaching a significant plateau $(P \leqslant 0.017)$ at 19 years post injury and then started improving. The spine BMD in our patient population never significantly decreased, and started improving as the age of the injury increased. Findings presented for the femoral regions were similar to other investigators' findings; however, the steady bone mass maintained in the lumbar area, which increased with age regardless of the age of the injury, with the bone mass loss in the hip area, were the most notable new findings.
\end{abstract}

Keywords: spinal cord injury; spinal cord injury associated bone mass loss; bone mineral density (BMD); dual energy X-ray absorptometry (DEXA)

\section{Introduction}

In the USA there are approximately 10,000 new spinal cord injured individuals annually. The life span of these individuals has been gradually increasing, approaching normal levels at the present time. One of the complications of spinal cord injury is the associated bone mass loss. Bone mass loss can be complicated by fracture, further disabling the patient. Preventive measures are important to maintain the quality of life in these individuals. Although spinal cord associated bone mass loss (SABL) is believed to be associated with immobilization, its pathogenesis is neither precisely documented nor well understood. Most previous studies of this type of immobilization osteoporosis used either secondary skeletal indices such as urinary calcium and collagen products ${ }^{1-7}$ or bone histomophometry. ${ }^{8-11}$ More precise and accurate measurements of bone mass have become available with the development of bone densitometers.

Measurement of bone mineral content (BMC) or bone mineral density (BMD) after spinal cord injury in an attempt to quantify bone loss has been reported in

Correspondence: SM Szollar, VAMC-SCI Center, 3350 La Jolla Village Drive, San Diego, CA 92161, USA only a few publications. Early studies primarily measured $\mathrm{BMC}$ at the distal radius. ${ }^{12,13}$ Later studies included either BMC or BMD measurements of the lower extremities. ${ }^{4,14-21}$ These studies were performed on small patient populations and did not take into account the length of time of injury nor the age of the patient. The purpose of the present preliminary study was threefold: (1) to assess if changes in bone mass using substantial numbers of patients were consistent with previous reports using small patient populations; (2) to determine if these changes were age related; and (3) to determine when these changes began to appear.

\section{Materials and methods}

\section{Selection and grouping of the participants}

Laboratory studies including complete blood count (CBC) with differential, erythrocyte sedimentation rate (ESR), electrolytes, liver and renal function studies, standard X-rays, and BMDs were performed on 320 young active duty military, mid-age and older male veterans (80 able-bodied individuals and 240 male patients with spinal cord injuries who had been 
admitted to the spinal cord injury unit at the Veterans Affairs Medical Center from 1994 to 1995). This initial spinal cord injured patient population included new patients with acute injuries as well as patients readmitted for various medical reasons. Only subjects with normal laboratory findings and no clinically obvious indications of heterotopic ossification were included in the BMD studies. None of the controls or patients had metabolic diseases or other conditions known to influence their calcium metabolism or BMD, and, none of the participants had received treatment influencing these parameters. No spinal cord injured subjects with internal fixation devices were included in any part of the study.

Based on the selection criteria 69 able-bodied individuals (mean age $=51.1 \pm 1.7$ years, range $24-76$ years) and 135 spinal cord-injured patients (mean age $=48.8 \pm 1.3$ years, range $20-78$ years) were included in the study. Since differential changes in BMD of the appendicular and axial skeleton with aging have been shown to occur in twenty year intervals, ${ }^{22-24}$ able-bodied individuals and patients were stratified into three 20 year age-groups $(20-39$, $40-59$, and $60+$ years of age). Patients within each age group were further stratified according to the time since their injury occurred (less than one year, 1-5 years, $6-9$ years, $10-19$ years, $20-29$ years, $30-39$ years, 40-49 years, and 50-59 years). Table 1 summarizes the stratification of able-bodied and spinal cord injured males according to age, completeness of injury, and age of injury.

Methods

Bone mineral density measurements $\left(\mathrm{g} / \mathrm{cm}^{2}\right)$ of the lumbar spine $(\mathrm{L} 2-\mathrm{L} 4)$ and three regions of the proximal femur (the femoral neck, Ward's triangle, and the trochanteric regions) were obtained using dual energy X-ray absorptiometry (DEXA) (LUNAR Model DPX; LUNAR CORP., Madison, WI). Spine BMD was assessed both at individual levels and as average density of L2-L4. Overall BMD of the lumbar

Table 1 Summary of the stratification of able-bodied and spinal cord injured males according to age, completeness of injury, and time since injury

\begin{tabular}{|c|c|c|c|c|c|c|c|c|c|c|c|}
\hline & $\begin{array}{c}\text { Overall } \\
\text { age of } \\
\text { controls }\end{array}$ & $\begin{array}{l}\text { Overall } \\
\text { age of } \\
\text { patients }\end{array}$ & $\begin{array}{c}\text { Average } \\
\text { time } \\
\text { injury } \\
\text { (year) }\end{array}$ & $0-1$ & $1-5$ & $\begin{array}{c}\text { Stratifica } \\
6-9\end{array}$ & $\begin{array}{c}\text { tion by a } \\
10-19\end{array}$ & $\begin{array}{c}\text { ge of inju } \\
20-29\end{array}$ & $\begin{array}{c}\text { ry (year) } \\
30-39\end{array}$ & $40-49$ & $50-59$ \\
\hline \multicolumn{12}{|l|}{$20-39$ year olds } \\
\hline - mean age & 31.3 & 30.3 & 5.3 & 27.6 & 28.0 & 30.3 & 36.1 & & & & \\
\hline - st. error & 1.2 & 0.9 & 1.0 & 1.1 & 2.2 & 0.9 & 0.6 & & & & \\
\hline - range & $24-39$ & $20-39$ & $0.08-17$ & $20-33$ & $21-37$ & $29-32$ & $33-39$ & & & & \\
\hline $\begin{array}{l}\text { - completeness of injury } \\
\text { complete paraplegia }\end{array}$ & & 10 & 10 & 2 & 4 & 0 & 4 & & & & \\
\hline incomplete paraplegia & & 7 & 7 & 4 & 2 & 1 & 0 & & & & \\
\hline complete tetraplegia & & 15 & 15 & 7 & 2 & 1 & 5 & & & & \\
\hline incomplete tetraplegia & & 4 & 4 & 1 & 1 & 1 & 1 & & & & \\
\hline - number & 14 & 36 & 36 & 14 & 9 & 3 & 10 & & & & \\
\hline \multicolumn{12}{|l|}{$40-59$ year olds } \\
\hline - mean age & 49.7 & 47.5 & 17.7 & 41.8 & 51.2 & 50.0 & 44.4 & 47.0 & 52.4 & & \\
\hline - st. error & 0.9 & 0.7 & 1.3 & 1.2 & 1.8 & 1.8 & 1.2 & 0.9 & 1.1 & & \\
\hline - range & $41-59$ & $40-58$ & $0.17-34$ & $40-45$ & $47-57$ & $47-58$ & $50-53$ & $40-58$ & $48-56$ & & \\
\hline $\begin{array}{l}\text { - completeness of injury } \\
\text { complete paraplegia }\end{array}$ & & 16 & 16 & 0 & 0 & 2 & 4 & 9 & 1 & & \\
\hline incomplete paraplegia & & 8 & 8 & 1 & 2 & 0 & 2 & 2 & 1 & & \\
\hline complete tetraplegia & & 29 & 29 & 3 & 2 & 4 & 5 & 10 & 5 & & \\
\hline incomplete tetraplegia & & 5 & 5 & 0 & 2 & 0 & 1 & 1 & 1 & & \\
\hline - number & 37 & 58 & 58 & 4 & 6 & 6 & 12 & 22 & 8 & & \\
\hline \multicolumn{12}{|l|}{$60+$ year olds } \\
\hline - mean age & 69.3 & 67.1 & 22.1 & 68.0 & 64.3 & 68.8 & 67.8 & 63.2 & 65.3 & 67.7 & 73.3 \\
\hline - st. error & 1.0 & 0.9 & 2.9 & 2.5 & 1.0 & 3.0 & 3.3 & 1.8 & 2.7 & 2.0 & 2.6 \\
\hline - range & $60-76$ & $60-78$ & $0.08-52$ & $63-78$ & $62-69$ & $61-64$ & $60-76$ & $60-70$ & $61-73$ & $62-75$ & $67-78$ \\
\hline - completeness of injury & & 17 & 17 & 2 & 2 & 2 & 4 & 1 & 1 & 2 & 3 \\
\hline incomplete paraplegia & & 9 & 9 & 1 & 2 & 1 & 0 & 1 & 0 & 3 & 1 \\
\hline complete tetraplegia & & 9 & 9 & 2 & 0 & 1 & 0 & 1 & 3 & 2 & 0 \\
\hline incomplete tetraplegia & & 6 & 6 & 1 & 2 & 0 & 1 & 2 & 0 & 0 & 0 \\
\hline - number & 18 & 41 & 41 & 6 & 6 & 4 & 5 & 5 & 4 & 7 & 4 \\
\hline Total & 69 & 135 & 135 & 24 & 21 & 13 & 27 & 27 & 12 & 7 & 4 \\
\hline
\end{tabular}


spine was determined as the total BMD in the 2nd, 3 rd, and 4th vertebrae.

BMD measurements of both controls and patients were calculated as a percent of the standardized parameters for healthy non-selected age-matched men provided by the densitometry manufacturer. BMD measurements of patients were then compared to their age-matched controls. Mean and standard error of the mean were calculated for each age group. Statistical analysis was conducted using analysis of variance (ANOVA) followed by a post hoc analysis using Tukey's honest significance difference (HSD) test.

\section{Results}

Figure 1 shows the results of the initial BMDs for the lumbar spine and femoral regions of all able-bodied controls compared to all the spinal cord injured participants regardless of age, level of injury, and age of injury. When grouped in this fashion, the following findings were noted: (1) the BMD of the lumbar spine region of the spinal cord injured participants was significantly higher than for the able-bodied controls

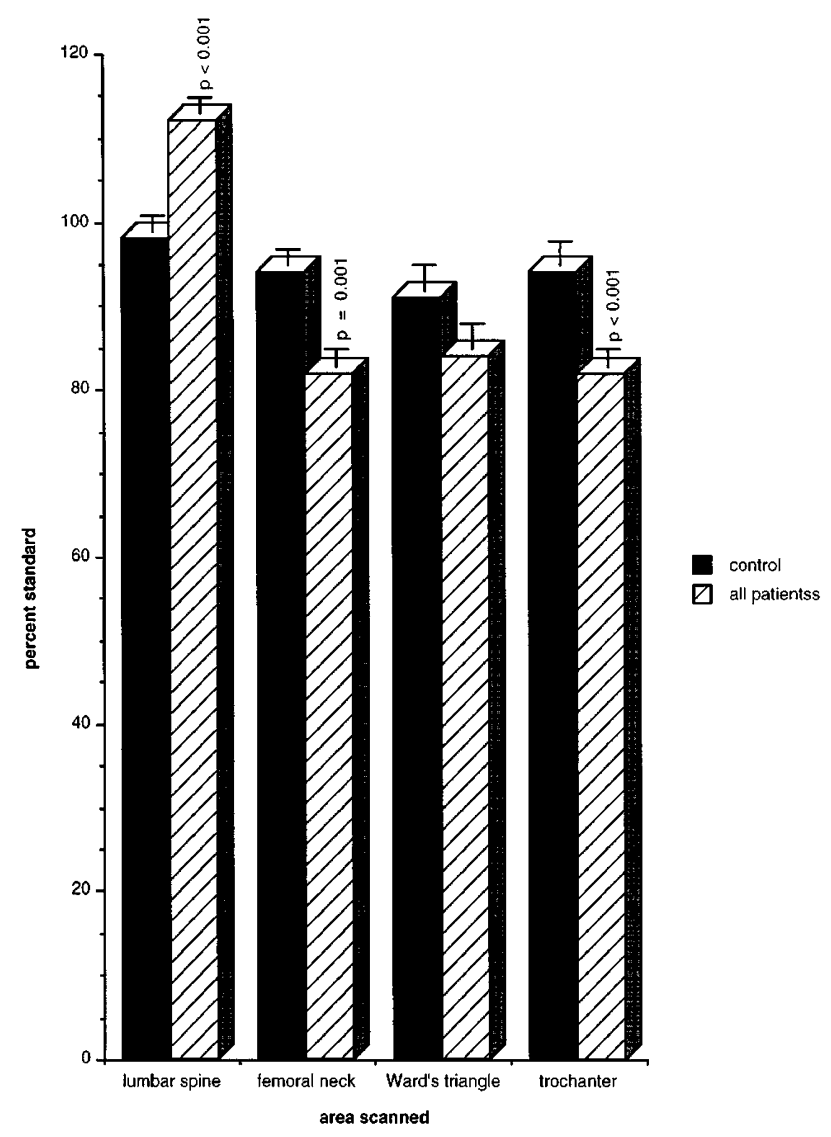

Figure 1 Comparison of the bone mineral densities (BMDs) of the lumbar spine, femoral neck, Ward's triangle, and the greater trochanter in able-bodied controls and the spinal cord injured patients regardless of the age of the patient and time since injured and (2) the BMDs of the femoral neck and the trochanter were significantly lower than the ablebodied controls, and (3) although the BMD of Ward's triangle was $8 \%$ lower than the able-bodied controls, it was not significantly different. Figures $2-4$ show the results of the BMDs of patients and controls after they were stratified into 20 year age groups in order to assess if these BMD differences were age related and to determine when these changes began to appear.

Figure 2 shows the results of the BMDs for both the lumbar and femoral regions in the 29-39 year old patients compared to the $20-39$ year old able-bodied controls. When these patients were grouped together, regardless of age of injury or the level of injury, there was no significant difference in the lumbar spine BMD; however, the femoral region BMDs were all significantly lower $(P=0.011$ for the femoral neck, $P=0.026$ for Ward's triangle and $P=0.009$ for the trochanter) in the spinal cord injured subjects than for their ablebodied controls (Figure 2A). When these patients were grouped according to the age of their injury (Figure $2 \mathrm{~B}-\mathrm{E}$ ), the following determinations were made: there was no significant difference in spinal or hip BMDs during the first year of injury; spinal region BMD decreased slightly during the following four years and then increased back to levels seen in the control subjects during the later years; all three femoral region BMDs increased slightly during the first year of injury and then significantly decreased over the following years $(P<0.001, P<0.002$, and $P<0.044$ for the femoral neck, Ward's triangle, and the trochanter, respectively).

Figure 3 shows the results of BMDs for both the lumbar and femoral regions in 40-59 year old patients compared to the 40-59 year old able-bodied controls. When these spinal cord injured patients were grouped together, regardless of age of injury or the level of injury, the BMD was higher $(P=0.012)$ in the lumbar spine, whereas the femoral region BMDs were all significantly lower $(P=0.001, P=0.027$, and $P=0.005$ for the femoral head, Ward's triangle, and the trochanter, respectively) than their able-bodied controls (Figure 3A). When these patients were grouped according to the age of their injury (Figure 3B-E), different profiles resulted. Although there was an increase in the BMD in the spinal regions over the years, the change was not significant. This increase began during years $1-5$ after injury. The femoral neck and Ward's triangle BMDs increased during the first year of injury, but then steadily decreased to below control levels over the next 15 years, reaching a level of significant difference for the femoral neck $(P=0.005)$ during years $10-19$ following injury. After year 19 , there was a slight increase in both regions, but in neither case did the BMD increase back to control levels. During the first year following injury, the BMD of the trochanter began to decrease. This decrease reached significant levels $(P=0.017)$ at years $10-19$ after injury. There was also an increase in the BMD in the 20-29 years following injury in the trochanter region and femoral regions. 




B. Lumbar Spine

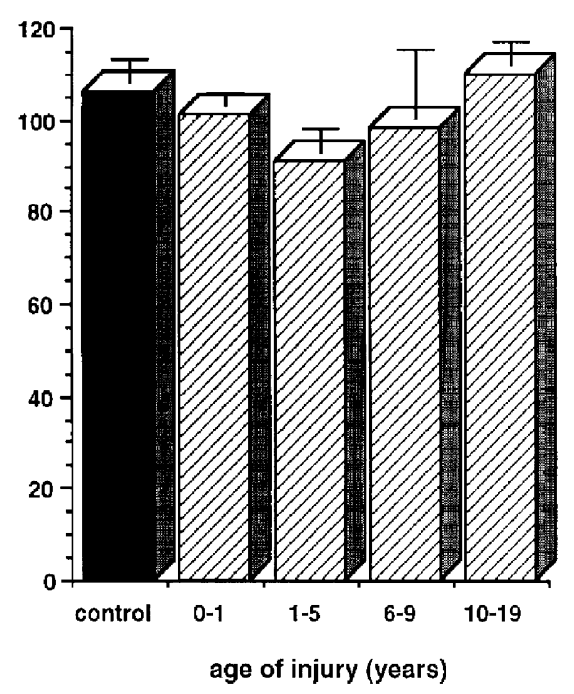

D. Ward's Triangle

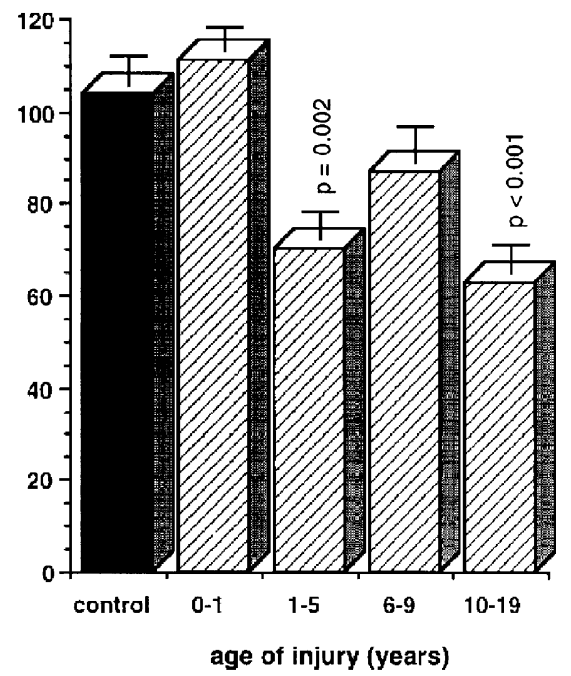

C. Femoral Neck



E. Trochanter

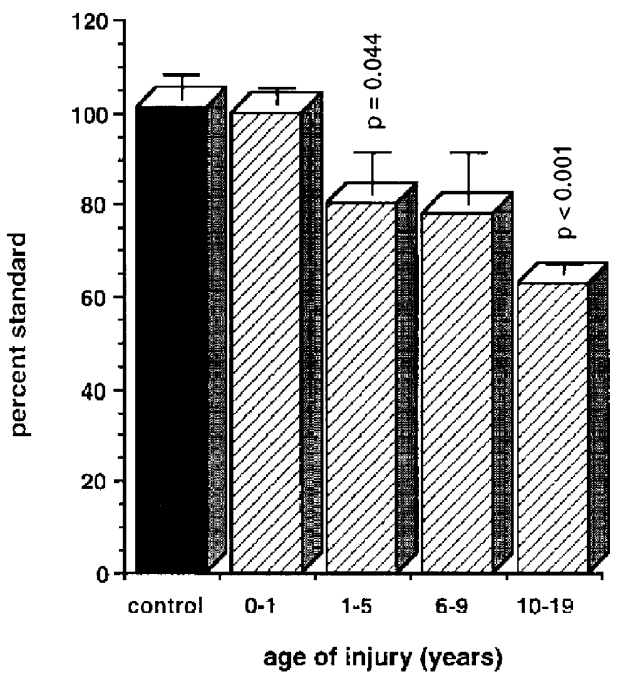

Figure 2 Comparison of the BMDs of the lumbar spine, femoral neck, Ward's triangle, and the greater trochanter in ablebodied controls and spinal cord injured patients with stratification according to age 

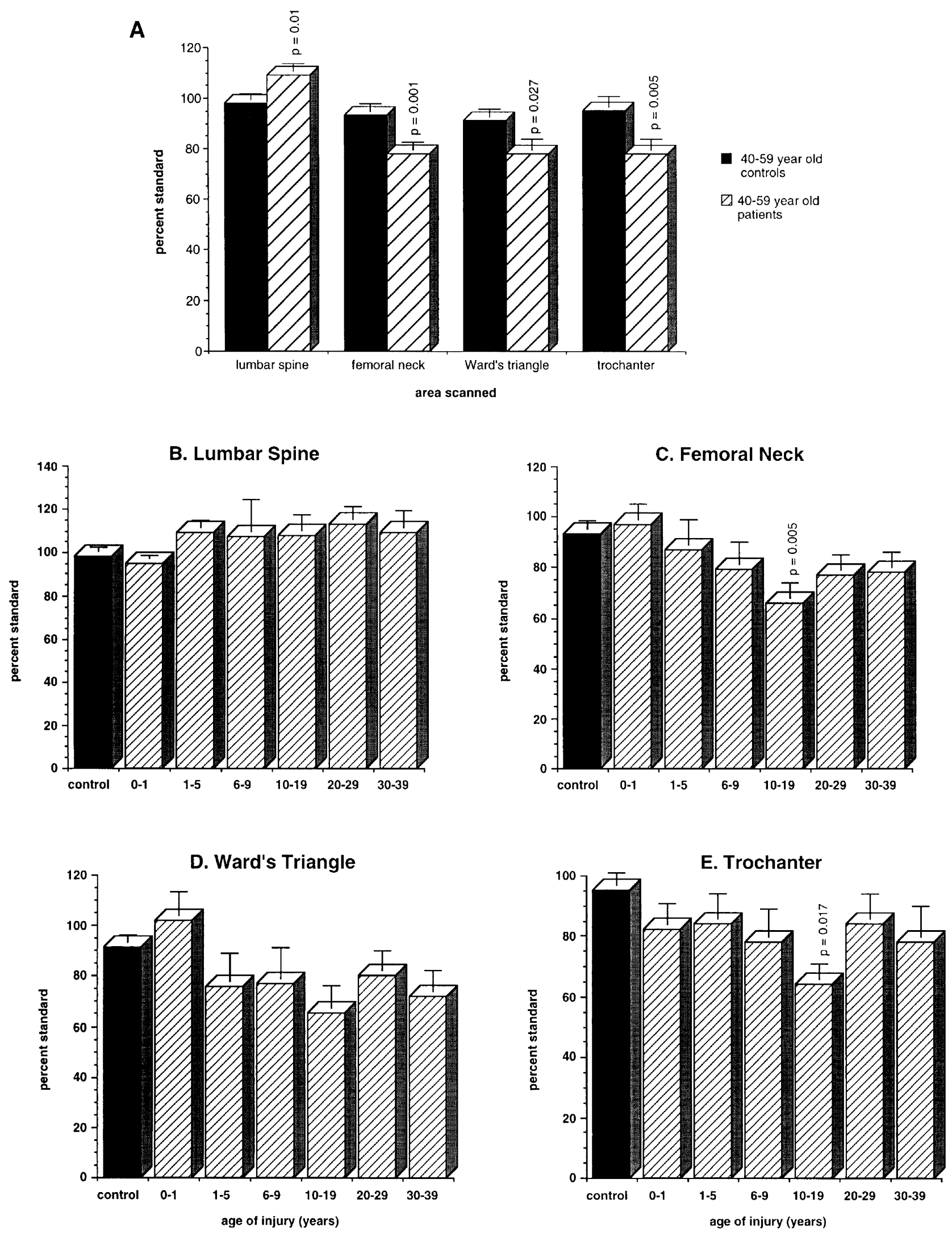

Figure 3 Comparison of the BMDs of the lumbar spine, femoral neck, Ward's triangle, and the greater trochanter in $40-59$ year old able-bodied controls and 40-59 year old spinal cord injured patients after the patients had been stratified according to the time since injured 


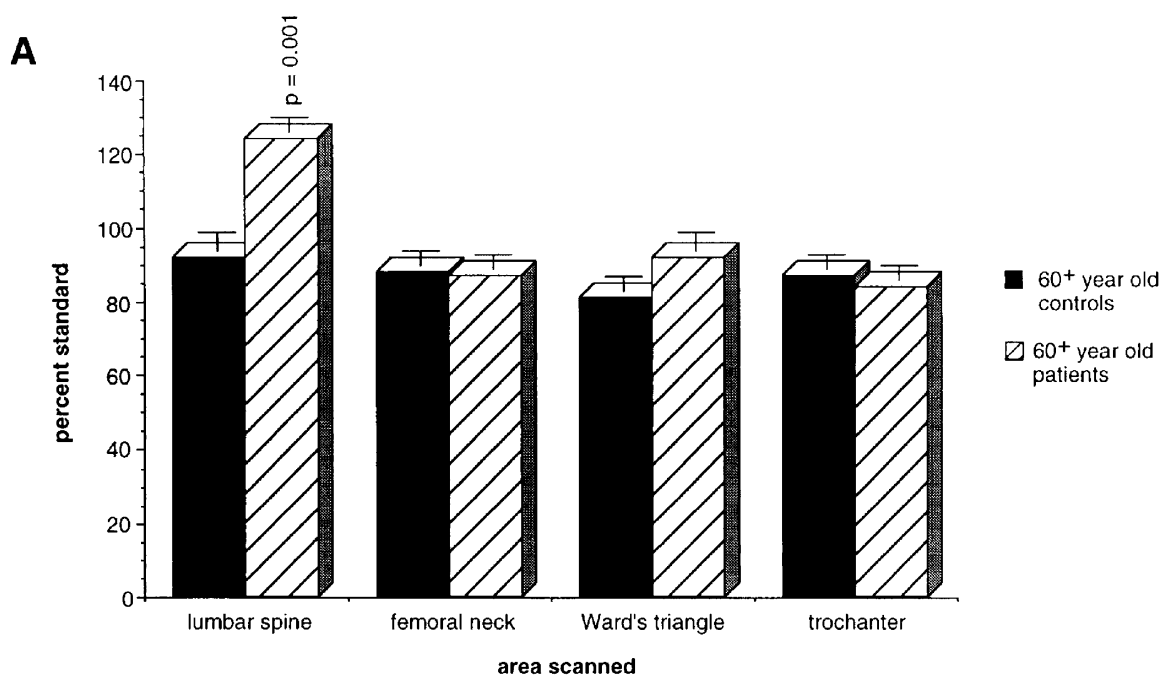

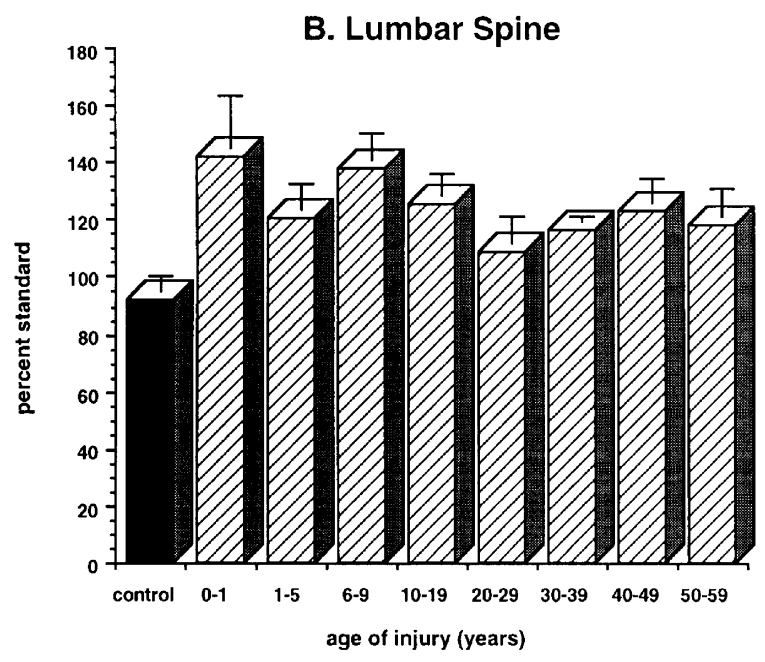

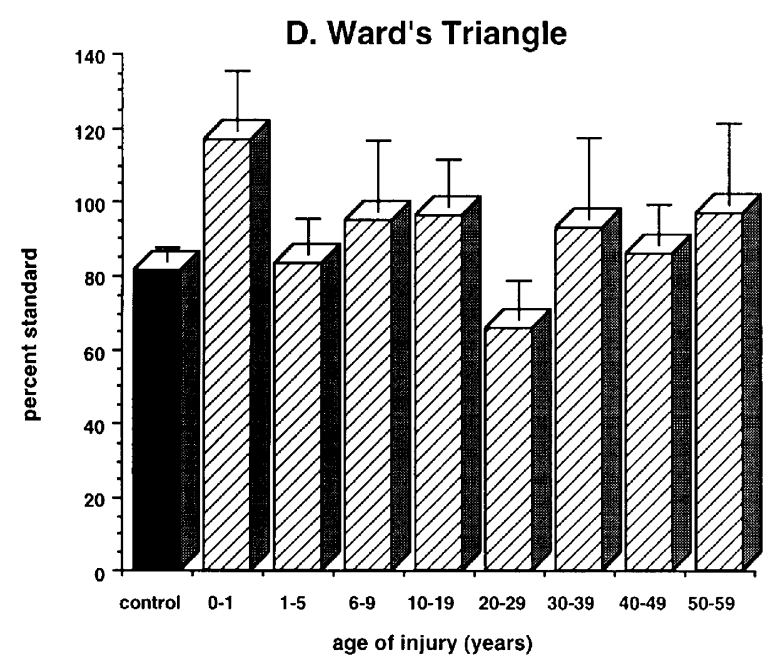

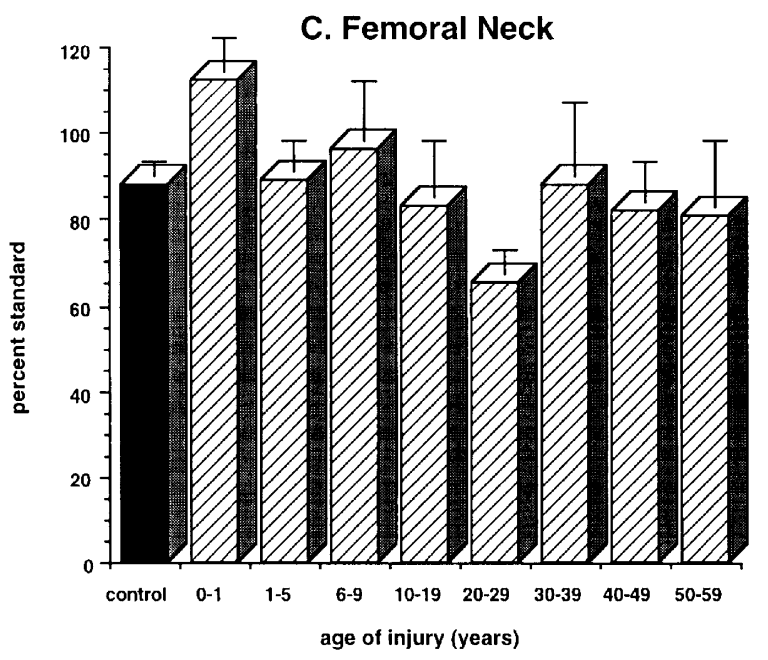

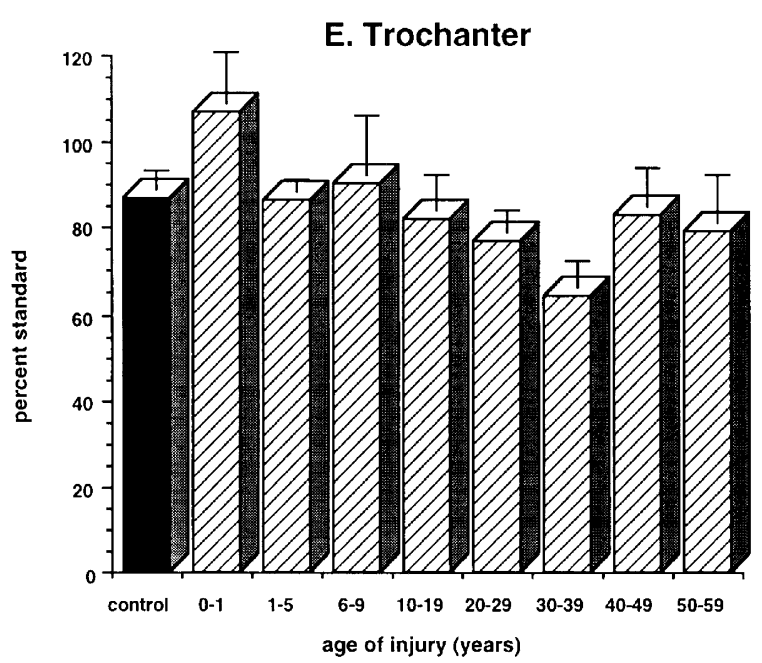

Figure 4 Comparison of the BMDs of the lumbar spine, femoral neck, Ward's triangle, and the greater trochanter in the $60+$ year old able-bodied controls and the $60+$ year old spinal cord injured patients after the patients had been stratified according to time since injury 
Figure 4 shows the results of BMDs for both the lumbar and femoral regions in $60+$ year old patients compared to the $60+$ year old able-bodied controls. There was a significant increase $(P<0.001)$ in the lumbar spine BMD when all the spinal cord injured patients were grouped together, regardless of the time since their injury or the level of injury (Figure 4A). There were no significant differences seen in the femoral regions when compared to their able-bodied age-matched controls. When patients were grouped according to the age of their injury (Figure $4 \mathrm{~B}-\mathrm{E}$ ), during the initial year there was an increase in the $\mathrm{BMD}$ of all four regions. There was then a decrease to control, or slightly below control levels, over the remaining years in all four regions. None of the differences in the BMDs in these regions reached significance.

\section{Discussion}

Precise and accurate methods for measuring bone mass have only recently been applied to studies in people with spinal cord injury. These studies are difficult to interpret because of the many methodological variations. From measurements of regional bone calcium accretion, Bergmann et $a l^{2}$ have shown an enhancement of bone calcium generalized to the whole skeleton in patients with spinal cord injury. Chantraine ${ }^{3}$ measured the outer and inner diameter of the femur and showed a significant increase in paraplegic patients. Garland et $a l^{18}$ concluded that bone mineral loss occurs throughout the entire skeleton. Uebelhart et $a l^{25}$ on the other hand, measured BMD of the lumbar spine and the lower limbs in male acute spinal cord injured subjects and found the mass of the lumbar spine to be stable, in sharp contrast to where the BMD was lower by $6.4 \%$. When we initially grouped our patients together (Figure 1), regardless of the age of the patient, level of injury, and the age at the time of injury, a significant increase of $14 \%$ in spinal bone mass and significant decrease ranging from $8-13 \%$ in the femoral regions was found. These results are contrary to Chantrine A et al ${ }^{15}$ and Uebelhart et $a l^{25}$ Possible reasons for the higher than normal BMD in the lumbar spine in our population might be that (1) the lumbar spine has become the primary weight bearing region or (2) neuropathic osteoarthropathy consisting of disk space loss, bone sclerosis, fragmentation, osteophytosis, and subluxation as well as degenerative disease which may have caused diffused increased radiodensity of the spinal column. ${ }^{26-28}$

Riggs et $a l^{22}$ showed that in normal men vertebral and appendicular bone diminution with aging was minimal or insignificant. In cross-sectional and longitudinal studies, Biering-Sorensen et al ${ }^{15,16}$ showed that BMC of the femoral bone was continuously and significantly decreased $(25 \%$ lower $)$ in spinal cord injured patients between the age of 20 and 55 compared to normal individuals, while the BMC of the lumbar spine was nearly unchanged. These results are similar to our spinal and femoral BMD results for patients between 20 and 39 years of age. For this age group, we obtained a nonsignificant $5 \%$ decrease in the BMD of the lumbar spine and significantly lower $(18 \%)$ BMDs of all three femoral regions of the 20-39 year old patients when compared to the able-bodied 20-39 year old controls. The BMD's of the femoral regions were also all significantly lower (approximately $16 \%$ ) in the $40-59$ year old patients, but were not different in the $60+$ year old patients. However, the BMD of the lumbar spine of both our $40-59$ year old and the $60+$ year old patients were significantly higher ( $11 \%$ and $35 \%$, respectively) than the $40-59$ year old and the $60+$ year old able-bodied controls, respectively. The only other group of osteoporotic subjects noted to maintain relatively more spinal bone mass was the group of females studied by Steiger et $a l^{23}$ over age 85 years. Biering-Sorensen et $a l^{16}$ stated that their longitudinal study indicated that normal muscle function and load bearing is necessary to prevent bone mass loss.

Garland et $a l^{18}$ using complete Frankel Class A traumatic paraplegic and tetraplegic spinal cord injured male patients under the age of 40 , found that equilibrium was reached by 16 months at two thirds of original bone mass near fracture threshold. Chantraine et $a l^{6}$ noted in paraplegics that the rapid loss of bone mass observed early (within the first 6 months of injury) in the iliac crest region is immediately followed by an increase, approaching those of normal subjects at 2 years post-injury. Minaire et al showed a $33 \%$ decrease in iliac crest trabecular bone volume prior to the 25th week of immobilization in spinal cord injured patients compared to controls. After this time, the trabecular bone volume became constant at a new, lower, steady state value. Biering et $a l^{16}$ investigated bone mineral content (BMC) with dual photon absorptiometry in eight spinal cord injured patients, at 9 days to 53 months post injury. They found the spine BMC unchanged. The femoral neck BMC decreased, reaching a steady state $60-70 \%$ of the normal values at about 24 months post injury. Wilmet et $a l^{20}$ have shown a rapid decrease of BMC in the paralysed areas of approximately $4 \%$ per month in areas rich in trabecular bone and approximately $2 \%$ per month in areas containing mainly compact bone. The temporal evolution of bone mass loss was assessed in small, general patient populations over short periods of time by various investigators. In our study, we investigated a large subject and control population with military background.

When our patients within the various age categories were grouped according to the length of time they had been injured (Figures 2-4), the following results were obtained. During the first year of injury patients between the age of 20 and 59 displayed a nonsignificant decrease in the BMDs of the spine and hip regions. The $60+$ year old patients, on the other hand, had a nonsignificant increase in the BMDs of the spine and hip regions during this time period. During years 
$1-5$ following injury, young patients $(20-39$ year old patients) continued to demonstrate bone mass loss (although not significant) in the lumbar region, followed by an increase to control levels after 5 years of injury. The BMDs of the lumbar region in both the 40-59 year old and the $60+$ year old patients were above control levels throughout, but never reached significant levels at any time. We noted an increase in all age groups in femoral region BMDs immediately after injury $(0-1$ years post injury) that declined over time and stabilized at $10-19$ years post injury. Only in patients aged 20-39 did this decline reach levels significantly lower than the age-matched controls. This decrease reached levels $30-40 \%$ lower than control levels before increasing to steady state levels $20 \%$ less than control levels. The BMD decline of the femoral regions in our 40-59 year old patients reached significance at $10-19$ years post injury. Patients injured for longer than 19 years showed no significant difference in spine BMD compared to age-matched controls.

Sharp et $a l,{ }^{19}$ studying men 5.6 days -48 years post injury, demonstrated that the lumbar spine BMD was unchanged compared to age matched controls. They also showed a BMD decrease of only $19 \%$ for the upper femur but did not indicate whether a steady state was reached in their patients. Uebelhart et $a l^{25}$ measured BMC and BMD of the lumbar spine and the lower and the upper limbs of six young male acute spinal cord injury subjects. They found stable bone mass in the lumbar spine in sharp contrast to the lower limbs where the BMC was lower by $7.1 \%$ and the BMD by $6.4 \%$. Although these findings utilized different methodologies, they seem to correlate with our findings.

From the data presented here and elsewhere, ${ }^{6,15,16,18,20,22,23,29}$ the natural history of bone mass loss appears to be different depending on whether it is due to immobilization, menopause, hormonal, or age related factors. The differences between our results and the studies available in the literature may be explained by the special population included in our study. The subjects were a mix of young active duty military, mid-age and older veteran population. The studies reported in the literature were conducted on the general patient population in private hospitals. Occupation and activity levels of the subjects were not evaluated. It may be that our study population has a higher baseline bone mass due to their military background. However, the data obtained from the control group recruited with similar background does not support this theory. Sun exposure in Southern California may prevent osteomalacia or at least vitamin D insufficiency which is said to be prevalent in all northern areas by the end of winter.

The pathogenesis of bone mass loss in spinal cord injury needs to be further investigated. The studies in progress utilizing newly developed assays and devices to assess bone metabolism and the effects of degenerative joint disease of the hip and neuropathic osteoarthropathy of the spine will provide more insight into mineralization disorders with spinal cord injury.

\section{Acknowledgements}

We are grateful to Stephen Martin for his skillful assistance. This study was supported by the Rehabilitation and Research Services of the Department of Veterans Affairs (grant \#B576-RA) and the National Institutes of Health.

\section{References}

1 Minaire $\mathrm{P}$ et al. Quantitative histological data on disuse osteoporosis: Comparison with biological data. Calcified Tissue Research 1974; 17: $57-73$.

2 Bergmann $\mathrm{P}$ et al. Longitudinal study of calcium and bone metabolism in paraplegic patients. Paraplegia 1977-78; 15: $147-159$.

3 Chantraine A. Actual concept of osteoporosis in paraplegia. Paraplegia 1978 - 79; 16: 51 - 58

4 Minaire $\mathrm{P}$ et al. Effects of disodium dichloromethylene disphosphonate on bone loss in paraplegic patients. $J$ Clinical Investigations 1981; 68: $1086-1092$.

5 Pilonchery G, Minaire R, Milan JJ, Revol A. Urinary elimination of glycoaminoglycans during the immobilization osteoporosis of spinal cord injury patients. Clinical Orthopedics and Related Research 1983; 174: $230-235$.

6 Chantraine A, Nusgens B, Lapiere ChM. Bone remodeling during the development of osteoporosis in paraplegia. Calcified Tissue International 1986; 38: $323-327$.

7 Ohry A, Shemesh Y, Zak R, Hwezberg M. Zinc and osteoporosis in patients with spinal cord injury. Paraplegia 1980; 18: $174-180$.

8 Bikle DD et al. Bone disease in alcohol abuse. Annuals of Internal Medicine 1985; 103: $42-48$

9 Jackson JA et al. Bone histomorphometry in hypogonadal and eugonadal men with spinal osteoporosis. J Clinical Endocrinology and Metabolism 1987; 65: 53-58.

10 Francis RM et al. Spinal osteoporosis in men. Bone and Mineral 1989; 5: 347 - 357.

11 Delichatsios HK, Lane JM, Rivlin RS. Bone histomorphometry in men with spinal osteoporosis. Calcified Tissue International 1995; 56: $359-363$.

12 Griffiths HJ, Orsi CJ, Zimmerman RE. Use of ${ }^{125} \mathrm{I}$ photon scanning in the evaluation of bone density in a group of patients with spinal cord injury. Investigative Radiology 1972; 7: $107-$ 111.

13 Griffiths HJ, Bushueff B, Zimmerman RE. Investigation of the loss of bone mineral in patients with spinal cord injury. Paraplegia 1976; 14: $207-212$.

14 Phillips CA, Petrofsky JS, Hendershot DM, Stafford D Functional electrical exercise. A comprehensive approach for physical conditioning of the spinal cord injured patient. Orthopaedics 1984; 7: 1112-1123.

15 Biering-Sorensen F, Bohr H, Schaadt O. Bone mineral content of the lumbar spine and lower extremities years after spinal cord lesion. Paraplegia 1988; 26: 293 - 301.

16 Biering-Sorensen F, Bohr HH, Schaadt OP. Longitudinal study of bone mineral content in the lumbar spine, the forearm and the lower extremities after spinal cord injury. European Journal of Clinical Investigation 1990; 20: $330-335$.

17 Bauman WA, Russell W, Wang J, Pierson RN. Reduced bone mineral density in the pelvis and lower extremities of subjects with paraplegia. Clinical Research 1992; 40: 413A.

18 Garland DE et al. Osteoporosis after spinal cord injury. $J$ Orthopaedic Research 1992; 10: $371-378$. 
19 Sharp CA et al. Bone turn over after spinal cord injury. Bone 1995; 16: 1865S.

20 Wilmet E et al. Longitudinal study of the bone mineral content and of soft tissue composition after spinal cord section. Paraplegia 1995; 33: 674-677.

21 Bohr H, Schaadt O. Bone mineral content of the femoral neck and shaft: Relation between cortical and trabecular bone. Calcified Tissue International 1985; 37: 340-344.

22 Riggs BL et al. Differential changes in bone mineral density of the appendicular and axial skeleton with aging. Relationship to spinal osteoporosis. J Clinical Investigation 1981; 67: 328 - 335 .

23 Steiger $\mathrm{P}$ et al. Age-related decrements in bone mineral density in women over 65. J Bone and Mineral Research 1992; 7: 625-632.

24 Favus MJ. Bone Density Reference Data. In: Favus MJ (ed) Primer on the Metabolic Bone Diseases and Disorders of Mineral Metabolism, 2nd edition Raven Press: New York 1993, pp $426-$ 430.
25 Uebelhart D et al. Early modifications of biochemical markers of bone metabolism in spinal cord injury patients: A preliminary study. Scandinavian Journal of Rehabilitation and Medicine 1994; 26: $197-202$.

26 Resnick D. Neuromuscular disorders. In: Resnick D (ed) Diagnosis of bone and joint disorders, 3rd edition. vol 5. WB Saunders: Philadelphia 1995, pp 3365-3406.

27 Jaovisidha $\mathrm{S}$ et al. Influence of spondylopathy in spinal cord injury on bone densitometry using dual energy X-ray absorptiometry 1996 in press.

28 Resnick D, Niwayama G. Degenerative disease of the spine. In: Resnick D (ed) Diagnosis of bone and joint disorders, 3rd edition, vol 5. WB Saunders: Philadelphia 1995, pp 1372-1462.

29 Palle S, Vico L, Bourrin S, Alexnadre C. Bone tissue response to four-month antiorthostatic bedrest: A bone histomorphometric study. Calcified Tissue International 1992; 51: 189-194. 